\title{
Stimulation of pyloric motility by intraduodenal dextrose in normal subjects
}

\author{
R HEDDLE, D FONE, J DENT, AND M HOROWITZ
}

From the Gastroenterology Unit and Department of Medicine, Royal Adelaide Hospital, Adelaide, South Australia

SUMMARY Recent studies suggest that the pylorus may play an important role in the regulation of the gastric emptying of nutrient liquids in man. Dextrose solutions in the range 5-25 g/dl have been reported to empty from the human stomach at a constant caloric rate of $2 \cdot 1 \mathrm{kcal} / \mathrm{min}$. This study examined, in 12 healthy volunteers, the effects of intraduodenal dextrose on pyloric motility. Dextrose solutions, $5,10,15$, and $25 \mathrm{gde} / \mathrm{dl}$ and saline solutions, 0.9 and $2.7 \mathrm{~g} / \mathrm{dl}$ were infused into the duodenum at $4 \mathrm{ml} / \mathrm{min}$ for 10 minutes. Antral, pyloric, and duodenal motility were monitored with sideholes and a sleeve sensor positioned across the pylorus. Significant increases in the rate of isolated pyloric pressure waves and in basal pyloric pressure were seen with 15 and $25 \mathrm{~g} / \mathrm{dl}$ dextrose $(p<0.02)$ and $2.7 \mathrm{~g} / \mathrm{dl}$ saline $(\mathrm{p}<0.05)$. The intensity and duration of the phasic and tonic pyloric motor responses to intraduodenal dextrose were dose dependent and correlated directly with the rate of calorie delivery $(p<0.005$ for each parameter). Intraduodenal delivery of dextrose at a rate in excess of $2 \cdot 1 \mathrm{kcal} / \mathrm{min}$ stimulates both phasic and tonic pyloric contraction. These changes in pyloric motility may contribute to the close regulation of the emptying of dextrose from the stomach.

The recent application of an adapted sleeve sensor and two point transmucosal potential difference measurement has made possible continuous recording of pyloric motility in man..$^{1-3}$ It has been shown, with this technique, that infusion of a lipid emulsion into the duodenum induces pressure waves and tone confined to a narrow zone (usually $<6 \mathrm{~mm}$ wide) of manometrically definable pylorus. ${ }^{3}$ Such pyloric motor responses have been shown to stop the emptying of barium from the stomach to the duodenum. ${ }^{+}$ These observations are consistent with the proposal that the pylorus may contribute significantly to regulation of the passage of nutrients from the stomach to the duodenum, albeit in concert with other variables such as proximal gastric tone, antral motility and duodenal motility. . $-7^{-}$

Whilst gastric emptying of isotonic liquids such as $0.9 \%$ saline closely approximates an exponential (or volume dependent) process, ${ }^{,-10}$ there is strong evidence that the emptying of dextrose solutions is

Address for correspondence: Dr John Dent. Gastroenterology Unit, Royal Adelaide Hospital, North Terrace, Adelaide, South Australia, 50(0).

Received for publication 21 April 1988. subject to close feedback control after a short initial period of rapid emptying. ${ }^{* 11}$ "Dextrose solutions in concentrations ranging from 5 to $25 \mathrm{~g} / \mathrm{dl}$ empty linearly at a reproducible calorie limited rate of $2 \cdot 1$ $\mathrm{kcal} / \mathrm{min}$ in $\operatorname{man}^{11}$ and $0.4 \mathrm{kcal} / \mathrm{min}$ in Macaca mulatta. "1 Furthermore, dextrose infused intraduodenally has been reported to induce inhibition of gastric emptying in proportion to the amount of dextrose delivered." The receptors which mediate this close control appear to lie beyond the pylorus and may be duodenal osmoreceptors ${ }^{1213}$ although there are some data which suggest that different liquid nutrients of identical osmolarity may vary in their effect on the rate of gastric emptying ${ }^{1+15}$ and in their site of action. ${ }^{\text {th }}$

The present study was primarily designed to examine the effects of a range of intraduodenal dextrose and saline infusions on pyloric motility in man. The principal hypotheses to be examined were that intraduodenal dextrose would induce localised pyloric pressure waves and increase basal pyloric pressure, and that the intensity and duration of these changes in pyloric motility would be directly related to the rate of calorie delivery. A subsidiary aim was 
to compare the motor responses to equiosmolar dextrose and saline solutions.

\section{Methods}

\section{SUBJECTS}

Studies were carried out on 12 healthy volunteers (seven men, aged 18-41 years, weight range 54-86 $\mathrm{kg}$ ) who had no history of gastrointestinal disease and were not taking any medication. Smoking was prohibited on the day of the test. The study protocol was approved by the Human Research Review Committee of the Royal Adelaide Hospital in January 1987 and written informed consent was obtained from each subject.

EXPERIMENTAL PROTOCOL

Each subject was studied in the morning after an overnight fast. The manometric assembly was positioned across the pylorus with the aid of two point transmucosal potential difference measurement. ${ }^{17}$ The duodenum was infused at a rate of $4 \mathrm{ml} /$ min with six solutions given in random order. The solutions given were $5,10,15$, and $25 \mathrm{~g} / \mathrm{dl}$ dextrose in water and 0.9 and $2.7 \mathrm{~g} / \mathrm{dl}$ sodium chloride in water; these solutions delivered $0 \cdot 8,1 \cdot 6,2 \cdot 4,4 \cdot 0,0$ and 0 $\mathrm{kcal} / \mathrm{min}$ respectively. Each infusion was given for 10 minutes and was preceeded by a 10 minute control period. Control periods were only started once there had been a return of the pyloric motor patterns to a basal state according to predefined criteria.

PRESSURE MEASUREMENT

The manometric assembly incorporated a $4 \mathrm{~cm}$ long sleeve sensor ${ }^{18}$ which had five sideholes spaced at $1 \mathrm{~cm}$ intervals along its length. The sideholes at each end of the sleeve sensor were used to record intraluminal pressure and transmucosal potential difference (TMPD) and are referred to as the antral and duodenal TMPD sideholes. There were two further antral sideholes at 2 and $4 \mathrm{~cm}$ from the orad end of the sleeve and three additional duodenal sideholes at 3 , 9 , and $12 \mathrm{~cm}$ from the aborad end of the sleeve. The test solutions were delivered into the duodenum through the sidehole $12 \mathrm{~cm}$ aborad to the end of the sleeve. The section of the manometric assembly immediately beyond the aborad end of the sleeve was very flexible in order to accommodate the curvature of the proximal duodenum without causing leverage on, or deformity of, the sleeve sensor. The catheter had a maximum external diameter of $5.2 \mathrm{~mm}$ and a cross sectional area of approximately $18 \mathrm{~mm}^{2}$ at the level of the sleeve sensor. Intubation of the pylorus was aided by a small articulated tungsten weight at the end of the assembly, $18 \mathrm{~cm}$ beyond the end of the sleeve.
The elements of the assembly were all perfused at $0.3 \mathrm{ml} / \mathrm{min}$ with an adapted pneumohydraulic pump. The antral and duodenal TMPD sideholes were perfused with normal saline from separate reservoirs, and all other channels were perfused with water from a third reservoir. Occlusion of the sideholes produced a pressure rise rate of $2500 \mathrm{~mm} \mathrm{Hg} / \mathrm{sec}$ whilst occlusion of the proximal, mid and distal sleeve resulted in rise rates of 460,80 , and $44 \mathrm{mmHg} / \mathrm{sec}$ respectively. Pressures were recorded with pressure transducers (Deseret Medical Inc, cat. no. 38-8000-1, Sandy, Utah, USA) interfaced to a 12 channel chart recorder (model 7D, Grass Inc, Quincy, Mass, USA). Tracings were obtained at a paper speed of $100-150 \mathrm{~mm} / \mathrm{min}$.

MEASUREMENT OF TRANSMUCOSAL POTENTIAL DIFFERENCE (TMPD)

Transmucosal potential difference was measured through saline columns perfusing the duodenal and antral TMPD sideholes. ${ }^{14}$ Each saline column was connected by an electrolyte bridge filled with $1 \mathrm{M} \mathrm{KCl}$ in $3 \%$ agar to a calomel half cell. The reference electrode was a saline filled subcutaneous cannula connected to a calomel half cell by an identical $\mathrm{KCl} /$ agar bridge. The TMPD at each sidehole was printed out continuously using a multichannel $\mathrm{PD} / \mathrm{pH}$ amplifier (model 1201, Biomedical Engineering Department, Flinders Medical Centre, Adelaide, Australia) interfaced to the chart recorder.

DATA ANALYSIS

Inclusion and exclusion of data

Records were only analysed when the sleeve was correctly placed across the pylorus. The criteria used to define correct positioning were that the duodenal TMPD was equal to or more positive than $-15 \mathrm{mV}$ whilst the gastric TMPD was equal to or more negative than $-20 \mathrm{mV}$. In addition the difference between the two readings was required to be at least $15 \mathrm{mV} .{ }^{3}$ Pressure waves sweeping from the antrum across the pylorus into the duodenum occasionally caused transient aboral displacement of the assembly; such waves were scored provided that, at the onset of the wave, the TMPD criteria for correct position were satisfied. Each control and infusion period and at least the first 10 minutes after completion of each infusion was divided into five minute epochs, starting from the beginning of the control period. Analysis of the postinfusion period was extended beyond 10 minutes if phasic or tonic pyloric response persisted beyond this time.

Pressure waves recorded by the sleeve sensor

Pressure waves of amplitude $\geq 10 \mathrm{mmHg}$ recorded by the sleeve sensor were classified as either isolated 
pyloric pressure waves (IPPWs) or non-localised pressure waves. ${ }^{3}$ To be scored as an IPPW a pressure wave had to satisfy two criteria. First, the wave had to be recorded by the sleeve in the absence of an associated wave of any amplitude recorded by either of the TMPD sideholes at each end of the sleeve. Second, as $92 \%$ of IPPWs are confined to a phasically active zone $<9 \mathrm{~mm}$ wide, ${ }^{3}$ the pressure wave could be recorded at an amplitude $\geq 10 \mathrm{mmHg}$ by no more than one of the sideholes between the TMPD sideholes that is, its width had to be $<1 \mathrm{~cm}$. Pressure waves recorded by the sleeve and TMPD sideholes were scored as associated when the onsets of their sharp upstrokes were within five seconds of each other. ${ }^{3}$

To minimise the effect of the interdigestive migrating motor cycle and any carryover effect from the preceding infusion, the motor pattern was allowed to settle to a basal pattern before the next infusion. Accordingly, each control period was preceded by a five minute period during which the rate of antral pressure waves, of amplitude $\geq 10 \mathrm{mmHg}$, in the sidehole $2 \mathrm{~cm}$ orad to the sleeve was $\leq 0.4 / \mathrm{min}$ and the rate of IPPWs was also $\leq 0 \cdot 4 / \mathrm{min}$. The duration of any IPPW response was scored by determining whether the mean IPPW rate in either of the five minute epochs during the test infusion exceeded $1 \cdot 0 /$ min and for how many consecutive epochs such a response persisted.

\section{Basal pyloric pressure}

Basal pyloric pressure was referenced to basal antral pressure and was derived from the sleeve tracing as a visual mean value for each minute by an independent observer blinded to the infusion sequence. A mean value was computed for the control period and for each five minute epoch of the infusion period. The duration of pyloric tone was defined as the number of consecutive minutes that $\propto$ basal pyloric pressure was $\geq 3 \mathrm{mmHg}$.

\section{Antral pressure waves}

Antral pressure waves were scored for the control and infusion periods and for at least 10 minutes after each infusion by counting the number of waves of amplitude $\geq 10 \mathrm{mmHg}$ recorded by the antral TMPD sidehole.

\section{Duodenal pressure waves}

Duodenal pressure waves were assessed by summing the number of pressure waves of amplitude $\geq 10$ $\mathrm{mmHg}$ recorded by the duodenal TMPD sidehole and by the sideholes 3 and $9 \mathrm{~cm}$ aborad to the sleeve. Episodes of regular duodenal pressure waves occurring at a frequency of $10-14 / \mathrm{min}$ for at least two minutes which were followed by duodenal quiescence were called phase-3-like. As a previous study ${ }^{2}$ has suggested that the relationship between antral motility and episodes of phase-3-like duodenal activity occurring in response to intraduodenal nutrients may differ from such episodes in the unstimulated state, the pattern of antral motility immediately preceding each episode was classified according to previously established criteria. ${ }^{20}$

\section{STATISTICAL ANALYSIS}

Data were analysed with the Wilcoxon's matchedpairs signed rank test and linear regression analysis. A $p$ value of less than 0.05 was considered significant for all analyses.

\section{Results}

In 10 subjects all six infusions were evaluated. In the remaining two subjects data were available for only two and four infusions. These studies were terminated prematurely because of proximal catheter displacement in one subject and vomiting in the other. Otherwise the infusions were well tolerated and subjects did not report nausea. The number of infusions made with each solution and the overall percentage of time in position for each are shown in the Table.

PYLORIC MOTILITY

Isolated pyloric pressure waves

These occurred infrequently during the control periods (median rate 0 waves $/ \mathrm{min}$, interquartile range $0-0.3$ ) and there was no significant change in

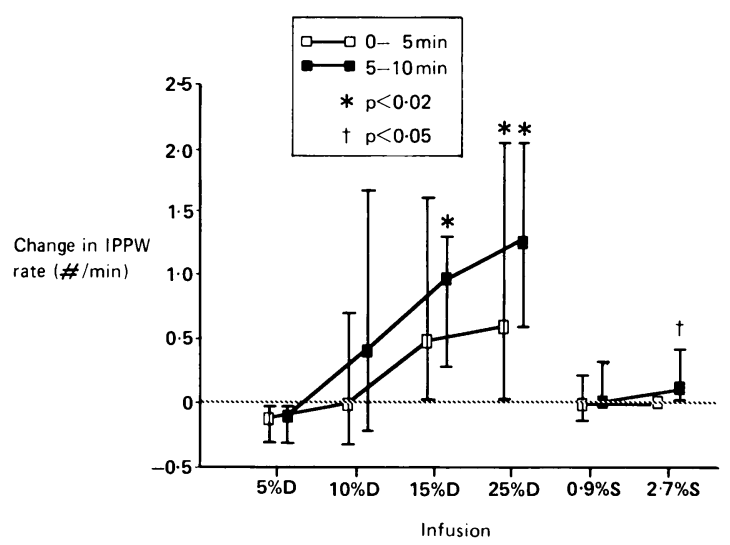

Fig. 1 Group data for the change in IPPW rate with each infusate during the first ( 0 to $5 \mathrm{~min}$ ) and second (5 to $10 \mathrm{~min}$ ) infusion epochs. In this and subsequent figures group data are presented as median and interquartile range. Dextrose is abbreviated as $D$ and saline as $S$. The $p$ values refer to those epochs in which the infusion induced a significant increase in the rate of IPPWs compared to the immediately preceeding control period. 
$\mathrm{mm} \mathrm{Hg}$
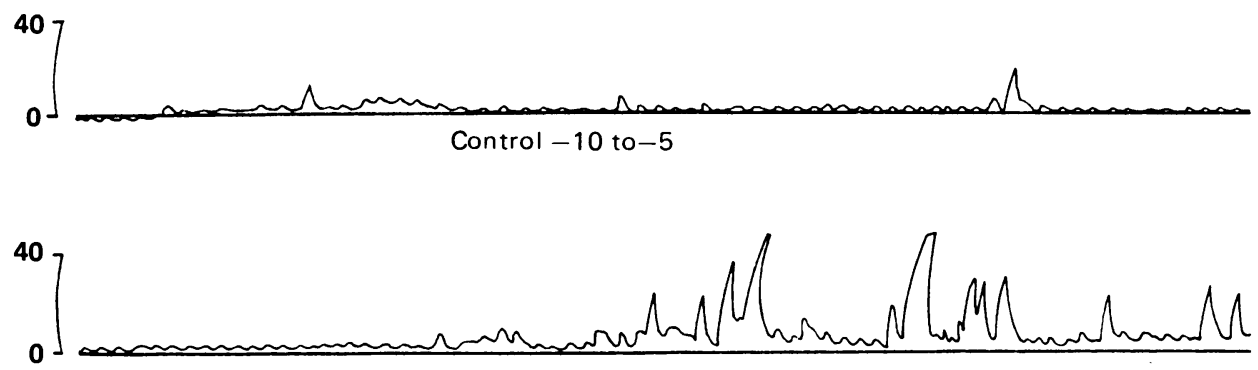

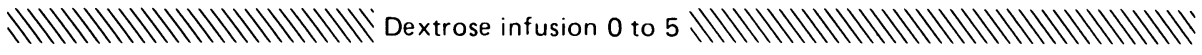
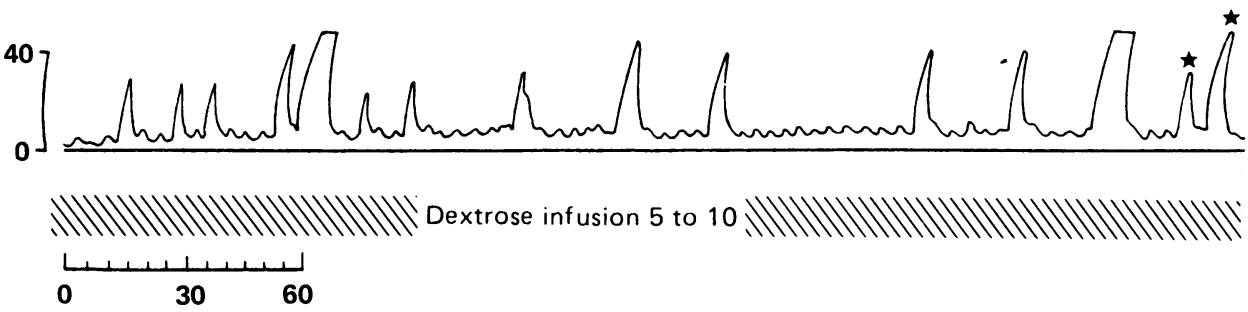

Time (s)

Fig. 2 Continuous pyloric pressure tracing showing the effect of intraduodenal infusion of $25 \%$ dextrose. All pressure waves of amplitude $\geq 10 \mathrm{mmHg}$ satisfied the criteria for an IPPW apart from the two waves marked with asterisks. Baseline indicates the basal antral pressure.

the rate of IPPWs in either epoch during $0.9 \%$ saline, $5 \%$, or $10 \%$ dextrose infusions (Fig. 1). During the latter five minute infusion epoch and for the overall infusion period, infusions of $15 \%$ and $25 \%$ dextrose and $2.7 \%$ saline were associated with a significant increase in the rate of IPPWs, as compared to the control period (Fig. 1). A typical example of the stimulation of IPPWs and basal pyloric tone by $15 \%$ or $25 \%$ dextrose is shown in Figure 2. The change in the rate of IPPWs during the infusion period was greater with $15 \%$ dextrose than with $2.7 \%$ saline $(p<0 \cdot 05)$. Although there was a trend for the change in IPPW rate to be greater for the second five minute infusion epoch than the first (Fig. 1), this did not reach statistical significance for any individual infusate, but was significant for the pooled data from all hyperosmolar dextrose infusions $(p<0.05)$ and from all hyperosmolar solutions $(p<0 \cdot 01)$. The duration of the IPPW response was significantly

Table Percentage of time that assembly was correctly positioned during each infusion

\begin{tabular}{lllllll}
\hline Infusion & $0 \cdot 9 \% \mathrm{~S}$ & $2 \cdot 7 \% \mathrm{~S}$ & $5 \% \mathrm{D}$ & $10 \% \mathrm{D}$ & $15 \% \mathrm{D}$ & $25 \% \mathrm{D}$ \\
Number & 12 & 11 & 10 & 11 & 10 & 12 \\
\% Time in place & $97 \%$ & $89 \%$ & $77 \%$ & $86 \%$ & $82 \%$ & $94 \%$ \\
\hline
\end{tabular}

greater with $15 \%$ and $25 \%$ dextrose infusions than with $0.9 \%$ saline or $5 \%$ dextrose infusions (Fig. 3).

There was a direct correlation between the change

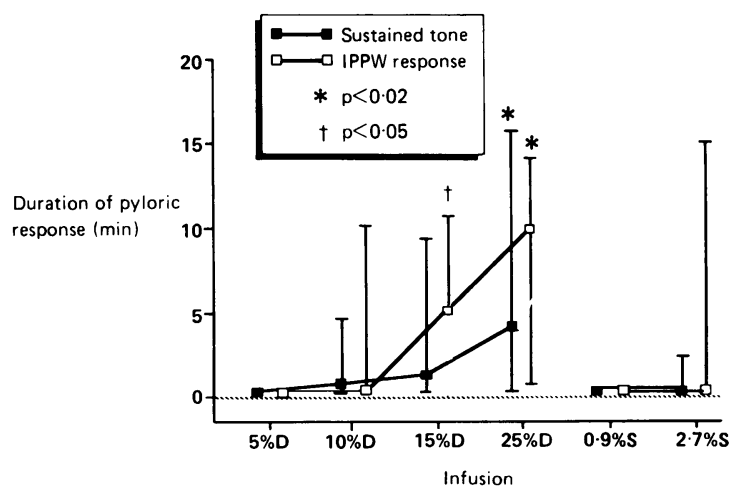

Fig. 3 Duration of the IPPW and pyloric tonic responses to each infusate. The durations of the IPPW responses to $15 \%$ and $25 \%$ dextrose were significantly greater than to $0.9 \%$ saline $(p<0.05$ and $p<0.02$ respectively) and to $5 \%$ dextrose $(p<0.02$ for both $)$. The duration of pyloric tone with $25 \%$ dextrose was greater than with $0.9 \%$ saline $(p<0.02)$ and with $5 \%$ dextrose $(p<0 \cdot 05)$. There was no statistical difference between the duration of the responses with $15 \%$ dextrose and with $2 \cdot 7 \%$ daline. 
$r=0.48, p<0.002$

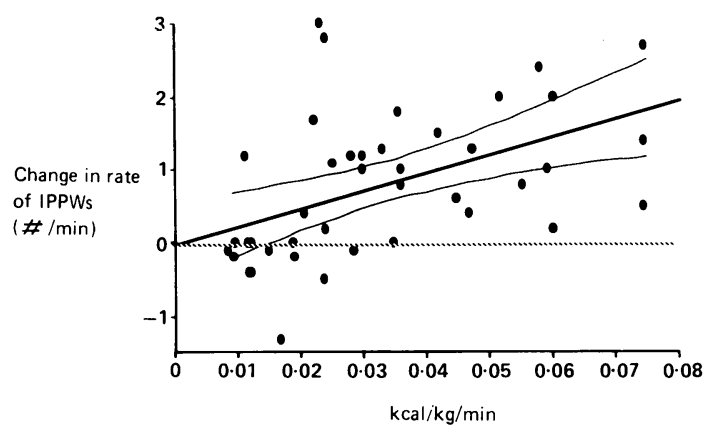

Fig. 4 Correlation between the rate of dextrose delivery ( $\mathrm{kcal} / \mathrm{kg} / \mathrm{min}$ ) and the change in rate of IPPWs during the second 5 min epoch of infusion. The least-squares linear regression line is shown with $90 \%$ confidence limits for the true mean of $y$.

in rate of IPPWs during the second five minute epoch of each dextrose infusion (as compared with the immediately preceding control infusion), the absolute rate of calorie delivery $(r=0.45, \mathrm{p}<0.005)$ and the rate of calorie delivery corrected for body weight $(r=0.48, p<0 \cdot 002)$ (Fig. 4). There was a significant correlation between the change in rate of IPPWs and the rate of calorie delivery when dextrose was infused at $\leq 0.03 \mathrm{kcal} / \mathrm{kg} / \mathrm{min}(\mathrm{r}=0.46, \mathrm{p}<0.05)$ but not when it was delivered at rates greater than this. A value of $0.03 \mathrm{kcal} / \mathrm{min} / \mathrm{kg}$ was chosen for this analysis on the basis of the previously shown rate of

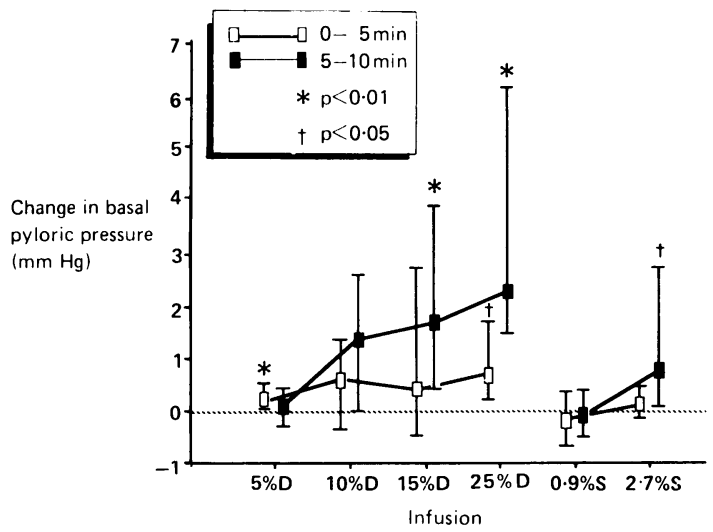

Fig. 5 Change in basal pyloric pressure with each infusate during the first ( 0 to $5 \mathrm{~min}$ ) and second ( 5 to $10 \mathrm{~min}$ ) infusion epochs. The $p$ values indicate those epochs in which the infusion was associated with a significant increase in basal pyloric pressure compared with the immediately preceding control period. The changes in basal pyloric pressure with $15 \%$ dextrose and $2.7 \%$ saline infusion did not differ significantly. emptying of dextrose of $2 \cdot 1 \mathrm{kcal} / \mathrm{min}$ divided by the median body weight of the group.

There was a direct correlation between the duration of the IPPW response seen with each dextrose infusion, the absolute rate of calorie delivery $(r=0.44, p<0.005)$ and the rate of calorie delivery corrected for body weight $(r=0 \cdot 50$, $\mathrm{p}<0 \cdot 001)$.

\section{Basal pyloric pressure}

The mean basal pyloric pressures during the control periods were tightly distributed about $0 \mathrm{mmHg}$ (overall median value $0 \mathrm{mmHg}$, interquartile range -0.5 to $+0.5 \mathrm{~mm} \mathrm{Hg}$ ). The group data for the change in basal pyloric pressure with each infusion are shown in Figure 5. The basal pyloric pressure during the second epoch was significantly greater than during the first epoch of the infusion period for $2.7 \%$ saline $(p<0 \cdot 05), 10 \%$ dextrose $(p<0 \cdot 02)$, and $15 \%$ and $25 \%$ dextrose infusions (both $\mathrm{p}<0 \cdot 01$ ).

There was a direct correlation between the change in basal pyloric pressure during the second five minute epoch of each dextrose infusion (as compared with the preceding control period), the absolute rate of calorie delivery $(r=0.54, p<0.0005)$ and the rate of calorie delivery corrected for body weight $(r=0 \cdot 66$, $\mathrm{p}<0.0001$ ) (Fig. 6). A positive correlation was seen when dextrose was infused at rates both $\leq$ and $>0.03$ $\mathrm{kcal} / \mathrm{kg} / \mathrm{min}(\mathrm{r}=0.60, \mathrm{p}<0.005$ and $\mathrm{r}=0.60, \mathrm{p}<0.01$ respectively).

Pyloric tone was absent in all but two of 64 analysable control periods. The duration of the stimulation of pyloric tone by infusates was significantly greater with $25 \%$ dextrose than with $5 \%$ dextrose or $0.9 \%$ saline (Fig. 3). There was a positive correlation between the duration of sustained pyloric tone seen with each dextrose infusion, the absolute

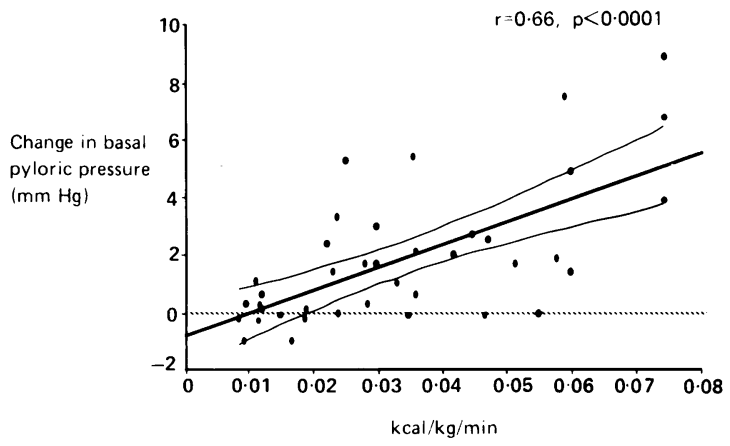

Fig. 6 Correlation between change in basal pyloric pressure and the duodenal delivery rate of dextrose ( $\mathrm{kcal} / \mathrm{kg} / \mathrm{min})$ for the second epoch of each infusion $(5-10 \mathrm{~min})$. The leastsquares linear regression line is shown with $90 \%$ confidence limits for the true mean of $y$. 


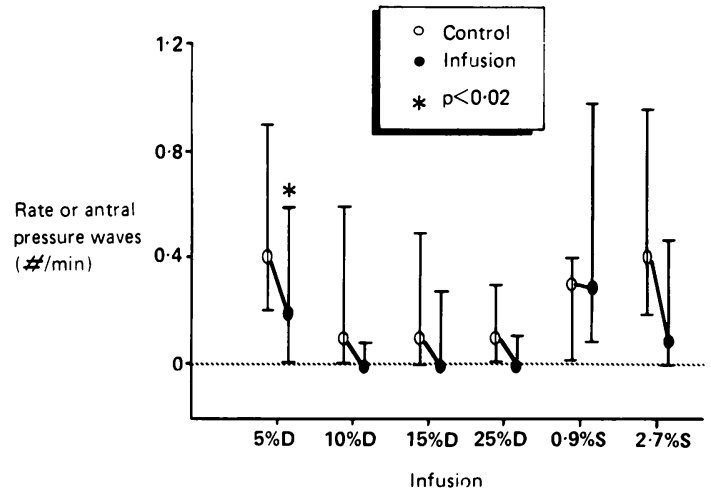

Fig. 7 Rate of antral pressure waves recorded by the most aborad antral sidehole during the control and infusion periods. There were significantly less pressure waves during the $5 \%$ dextrose infusion than during the preceding control period.

rate of calorie delivery $(\mathrm{r}=0.50, \mathrm{p}=0.001)$ and the rate of calorie delivery corrected for body weight $(\mathrm{r}=0 \cdot 68), \mathrm{p}<0 \cdot 0001)$.

\section{Relationship between IPPWs and basal pyloric pressure}

There was a direct correlation between the basal pyloric pressure and the rate of IPPWs during the first $(r=0.55)$ and second $(r=0.53)$ infusion epochs $(\mathrm{p}<0.0001$ for both) .

ANTRAL PRESSURE WAVES

Antral pressure waves occurred intermittently during the control periods, the median rate of such waves being $0 \cdot 2 / \mathrm{min}$ (interquartile range 0 to $0 \cdot 5 / \mathrm{min}$ ). There was a trend towards suppression of antral pressure waves with all infusions apart from $0.9 \%$

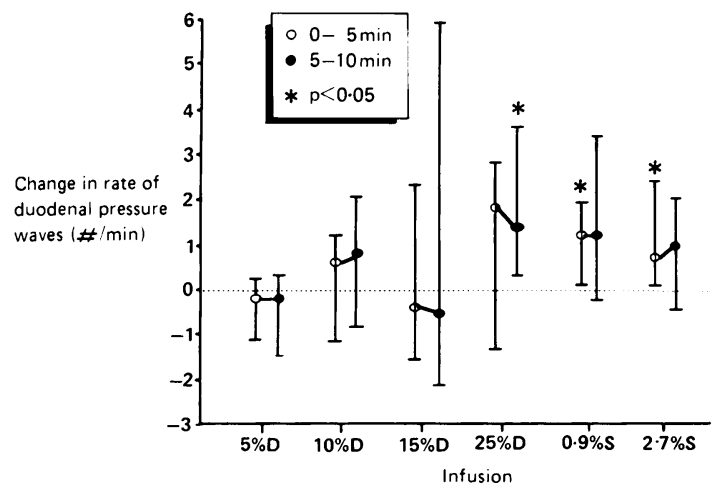

Fig. 8 Median change in the rate of duodenal pressure waves with each infusion. The rates in each epoch were compared to the rate during the preceding control period. saline (Fig. 7), which reached statistical significance for $5 \%$ dextrose $(p<0 \cdot() 2)$, for the pooled data from infusions of all hyperosmolar dextrose solutions $(\mathrm{p}<0 \cdot 01)$ and all hyperosmolar solutions $(\mathrm{p}<0 \cdot 01)$.

DUODENAL. PRESSURE WAVES

The basal rate of duodenal pressure waves varied markedly with time, presumably reflecting the duodenal interdigestive migrating motor cycle. There were significant increases in the rate of duodenal pressure waves as compared with the preceding control period during the first five minutes of $0.9 \%$ and $2.7 \%$ saline infusions and during the last five minutes of the $25 \%$ dextrose infusion (Fig. 8).

Regular duodenal pressure waves satisfying the criteria for 'phase-3-like' episodes were identified on 23 occasions, 13 occurred between infusions and at least 10 minutes after the end of the preceding infusion, five occurred during, or within 10 minutes of a saline infusion and five occurred during the infusion of hyperosmolar dextrose solutions (once each with 10 and $15 \%$ dextrose and three times with $25 \%$ dextrose). Those 'phase-3-like' episodes occurring between infusions, or in relationship to a saline infusion, were often preceded by frequent antral pressure waves (antral phase $2 a, 2 b$, and 3 in 4 , 8 , and 6 instances respectively). In contrast, there was complete antral suppression prior to all duodenal 'phase-3-like' episodes which occurred during a dextrose infusion.

\section{RELATIONSHIP BETWEEN PYIOORIC MOTILITY}

AND THE RATE OF ANTRAL PRESSURE WAVES

During the control periods there was no correlation between the rate of antral pressure waves and the rate of IPPWs or basal pyloric pressure $(r=0 \cdot 0)$, $p=0.7$ and $r=0.05, p=0.97$ respectively). During the infusion periods, however, the rate of antral pressure waves was inversely correlated with the rate of IPPWs $(r=0.35, p<0.005)$ and with the mean basal pyloric pressure $(\mathrm{r}=0.32, \mathrm{p}<0 \cdot 01)$.

\section{Discussion}

The present study has established, for the first time, that both IPPWs and increases in basal pyloric pressure occur promptly after infusion of dextrose into the duodenum. In addition, it has shown that the intensity and duration of these responses are related to the rate at which the dextrose is delivered. The stimulation of pyloric contraction occurred most predictably when dextrose was delivered at rates $(2 \cdot 4$ and $4.0 \mathrm{kcal} / \mathrm{min})$ which exceeded the rate $(2.1 \mathrm{kcal} /$ min) at which dextrose has been shown to empty from the stomach." Given that intraduodenal dextrose has been shown to cause a calorie depend- 
ent retardation of gastric emptying, " the findings of the present study are supportive of the concept that the pylorus may contribute to this closely regulated pattern of emptying by acting as a brake on gastric emptying.

Stimulation of localised pyloric contraction by an intragastric dextrose load has been reported in two previous studies. ${ }^{121}$ In the study of White et al, ${ }^{17}$ the method used only allowed brief recordings of pyloric motility and gave no information on the dose response relationship with dextrose. The motor patterns observed in this study are consistent with our findings. Houghton et al ${ }^{21}$ gave either $0.9 \%$ saline or $25 \%$ dextrose in $0.9 \%$ saline as the liquid phase of a radiolabelled solid liquid mixed meal. The rate of IPPWs during the emptying of the liquid and the duration of the solid lag period were significantly increased with dextrose, whilst the rate of liquid emptying decreased. It was inferred that these changes in gastric emptying and motility were the result of the delivery of dextrose into the duodenum, but the design of the study did not permit detailed analysis of the dose response relationship or the timing of the pyloric motor response to intraduodenal dextrose delivery.

The stimulation of IPPWs and basal pyloric tone is not unique to dextrose, as similar patterns of localised pyloric contraction have been reported in response to a lipid emulsion,, 3.37 and to the acidification of the duodenum." What is known about the mechanical properties of this localised pyloric contraction? Tougas et al ${ }^{4}$ observed the emptying of barium sulphate from the stomach of normal volunteers with fluoroscopy, and found that flow across the pylorus was absent during the time that IPPWs or pyloric tone $(>2 \mathrm{mmHg})$ were recorded by a sleeve sensor straddling the pylorus. Furthermore, IPPWs and tone were associated with the presence of a narrow zone of luminal closure between the antral and duodenal lumina. This latter finding is consistent with our previous observation that IPPWs and pyloric tone are confined to a narrow zone (usually $<6 \mathrm{~mm}$ wide) of manometrically definable pylorus. It seems most likely that this narrow zone reflects contraction of the distal pyloric muscle loop."."

The aetiology of the demonstrated latency in the phasic and tonic pyloric response to intraduodenal dextrose is unknown, but may reflect the initially lower intraluminal concentration of dextrose or the time taken for dextrose to be transported to duodenal or jejunal mucosal receptors. This observed latency may, at least in part, explain the observation that the initial phase of emptying of dextrose solutions may be faster than the subsequent rate. "11"11

The rate of caloric delivery consistently appeared to correlate better with the resulting pyloric motor responses after correction for body weight. This observation is compatible with previous work which showed that the rate of emptying of nutrient liquids from the stomach was faster in heavier subjects. ${ }^{2-}$ The absence of a correlation between the rate of calorie delivery when it exceeded $0.03 \mathrm{kcal} / \mathrm{kg} / \mathrm{min}$ and the resultant change in IPPW rate may reflect a maximal IPPW response. Such a finding is not unexpected, because other stimuli usually induce IPPWs with a maximum frequency of about three/minute. ${ }^{23}$ In contrast, there was no evidence of a plateau in the increase in basal pyloric pressure with increasing rates of dextrose delivery. The observed direct correlation between IPPWs and basal pyloric pressure is consistent with our previous observations that pyloric tone usually occurs together with IPPWs. inverse correlation between the rate of antral pressure waves and basal pyloric pressure during infusions is consistent with our previous observations that pyloric tone is rarely seen in the presence of antral pressure waves."

Is the observed response mediated by osmoreceptors or by more specific nutrient sensitive receptors? The present study does not give a definitive answer to this question, but does give support for the existence of dextrose sensitive receptors because the median changes in IPPW rate, basal pyloric pressure, duration of IPPW response and duration of pyloric tone were all greater for $15 \%$ dextrose than for the equiosmolar $2.7 \%$ saline solution. Whilst these differences reached statistical significance only for the change in rate of IPPWs, there was also a trend for $15 \%$ dextrose to induce greater and more consistent tonic responses than the $2.7 \%$ saline solution (Figs 3, 5). It is known that there are osmoreceptors in the human duodenum and that these receptors mediate slowing of gastric emptying by hyperosmolar solutions. ${ }^{2}$ Cooke ${ }^{15}$ found that gastric emptying in the dog was retarded by jejunal but not duodenal mucosal exposure to these solutions and also noted that jejunal glucose was a more potent retardant of gastric emptying than equiosmolar solutions of either saline or mannitol. The issue of whether receptors are responding to either osmolarity or calorie content alone, or to both of these factors, deserves further study.

The nature of the feedback pathways mediating the pyloric response to the infusion of dextrose into the duodenum is uncertain and has not been addressed in this study. The rapidity of the onset and offset of the response to intraduodenal dextrose is suggestive of a neural reflex mediated either by the vagal nerves ${ }^{25}$ or by the enteric nervous system. ${ }^{2 m-2 x}$ There is evidence in dogs of an excitatory cholinergic pathway within the enteric nervous system which passes orad within the duodenal wall to the pylorus 
and is excited by duodenal mucosal receptors. ${ }^{26}{ }^{27} \mathrm{~A}$ similar local neural reflex has also been described in cats, although in this species the pyloric response is blocked by naloxone but not by atropine. ${ }^{2 \times}$ Isolated pyloric pressure waves induced by intraduodenal lipid in man appear not to be blocked by naloxone, ${ }^{29}$ but recently completed human studies in our laboratory have shown that the IPPW response to dextrose is blocked by atropine, suggesting that a cholinergic pathway may also be present in man. ${ }^{31}$ The possibility of a hormonal mediator cannot, however, be totally dismissed as dextrose is known to cause the prompt local release of possible hormonal mediators such as cholecystokinin ${ }^{31}$ or gastric inhibitory polypeptide. ${ }^{32}$ It is also possible that hyperglycaemia, per se, may influence this response because hyperglycacmia, induced by the intravenous administration of dextrose, slows gastric emptying. ${ }^{3.3}$

It appears that multiple factors contribute to the regulation of gastric emptying. ${ }^{50.34}$ There is evidence that proximal gastric tone, ${ }^{16.34} .35$ antral pressure waves ${ }^{67}$ pyloric motility, ${ }^{46.34}$ and duodenal motility ${ }^{67}$ may all play a part. It is possible that a midgastric contraction band ${ }^{36}$ and the resistance of the small bowel to inflow ${ }^{34}$ may also be of importance. The demonstration of suppression of antral pressure waves by hypertonic dextrose infusates in the present study is consistent with previous studies which incidate that the antrum is suppressed during the delivery of nutrients into the duodenum ${ }^{23617}$; such suppression has been shown to be associated with slowing of gastric emptying. ${ }^{.21}$

The changes in duodenal motility observed in the present study are harder to interpret. The occurrence of 'phase-3-like' episodes in the duodenum has been described in response to a range of stimuli infused into the duodenum. ${ }^{237}$ This pattern of motor response may be a mechanism for rapid clearance of the duodenal lumen. The changes in the rate of occurrence of duodenal pressure waves seen with dextrose and saline were small in magnitude compared with the spontaneous variation in duodenal pressure wave rate, and so need to be interpreted with care. Nevertheless, the observation of a significant initial increase in the rate of duodenal pressure waves with both saline solutions, but not with the dextrose solutions, is intriguing and merits further study with a recording and data analysis approach that allows more detailed analysis of patterns of duodenal motility.

It should not be assumed that an entirely stereotyped pattern of modification of gastric, pyloric and duodenal motility occurs when emptying is being retarded. In the dog, the infusion of maltose into the proximal small bowel has relatively little effect on proximal gastric tone, whilse the delivery of lipid to the same site is a potent stimulus for proximal gastric relaxation. ${ }^{\text {th }}$ Both of these nutrients are known to retard gastric emptying ${ }^{3+}$ and dextrose and lipid when delivered intraduodenally induce localised phasic and tonic pyloric contraction. Adequate definition of the relative roles of the motor components believed to control gastric emptying requires the evaluation of a single stimulus by simultaneous recordings from the various components. Such an approach is challenging, but feasible, in the light of improvements of methods for recording of proximal gastric tone $e^{16.35}$ and the application of the sleeve for monitoring of pyloric motility."

The stimulation of IPPWs and increased basal pyloric pressure observed in the present study suggests that dextrose exerts feedback regulation of pyloric motility through duodenal or proximal jejunal receptors. This pattern of pyloric motility stimulated by intraduodenal dextrose has been shown to obstruct flow across the pylorus. ${ }^{+} \mathrm{We}$ propose that this pattern of localised pyloric contraction plays a role in the calorie limited emptying rate of dextrose solutions.

This work has been presented in abstract form to the Gastroenterological Society of Australia. The Australian National Health and Medical Research Council supported this work with a project grant and a Postgraduate Medical Research Scholarship held by Dr Heddle. The able technical support of Miss P Kocyan is acknowledged.

\section{References}

1 Houghton LA, Read NW, Heddle R, et al. Motor activity of the gastric antrum, pylorus, and duodenum under fasted conditions and after a liquid meal. Gastroenterology 1988; 94: 1276-84.

2 Heddle R, Dent J, Read NW, et al. Antropyloroduodenal motor responses to intraduodenal lipid infusion in healthy volunteers. Am J Physiol 1988; 254 (Gastrointest Liver Physiol 17): G671-9.

3 Heddle R, Dent J, Toouli J, Read NW. Topography and measurement of pyloric pressure waves and tone in humans. Am J Physiol 1988; 255 (Gastrointest Liver Physiol 18). (In press).

4 Tougas G, Anvari M, Richards D, Dent J, Somers S, Stevenson GW. Relationship of pyloric motility to transpyloric flow in healthy subjects [Abstract]. (jastroenterology 1987; 92: 1673.

5 Meyer J. Motility of the stomach and gastroduodenal junction. In: Johnson LR, ed. Physiology of the gastrointestinal tract. New York: Raven Press, 1986: 613-29.

6 Keinke O. Schemann M. Ehrlein H-J. Mechanical factors regulating gastric emptying of viscous nutrient meals in dogs. QJ Exp Physiol 1984; 69: 781-95. 
7 Weisbrodt NW. Wiley JN, Overholt BF. Bass P. A relationship between duodenal muscle contractions and gastric emptying. Gut 1969; 10: 543-8.

8 Hunt JN. Spurrell WR. The pattern of emptying of the human stomach. J Physiol (Lond) 1951; 113: 157-68.

9 Collins PJ, Horowitz M, Cook DJ, Harding PE. Shearman DJC. Gastric emptying in normal subjects - a reproducible technique using a single scintillation camera and computer system. Gut 1983; 24: 1117-25.

10 McHugh PR, Moran TH. Calories and gastric emptying: a regulatory capacity with implications for feeding. $\mathrm{Am} \mathrm{J}$ Physiol 1979; 236 (Regulatory Integrative Comp Physiol 5): R254-60.

11 Brener W. Hendrix TR. McHugh PR. Regulation of the gastric emptying of glucose. Gastroenterology 1983; 85: 76-82.

12 Mecroff JC, Go VLW, Phillips SF. Control of gastric emptying by osmolality of duodenal contents in man. Gastroenterology 1975; 68: 1144-51.

13 Hunt JN. A possible relation between the regulation of gastric emptying and food intake. Am J Physiol 1980; 239 (Gastrointest Liver Physiol 2): Gl-4.

14 Cooke AR. Gastric emptying in the cat in response to hypertonic solutions and tryptophan. Dig Dis 1978; 23: $312-5$.

15 Cooke AR. Localization of receptors inhibiting gastric emptying in the gut. Gastroenterology 1977; 72: 875-80.

16 Azpiroz F. Malagelada J-R. Intestinal control of gastric tone. Am J Physiol 1985; 249 (Gastrointest Liver Physiol 12): G501-9.

17 White CM, Poxon V. Alexander-Williams J. Effects of nutrient liquids on human gastrointestinal motor activity. Gut 1983; 24: 1109-16.

18 Dent J. A new technique for continuous sphincter pressure measurements. Gastroenterology 1976; 71: $263-7$.

19 Orlando RC. Powell DW. Bryson JC, et al. Esophageal potential difference measurements in esophageal discase. Gastroenterology 1982; 83; 1026-32.

20 Dent J, Dodds J, Sekiguchi T, Hogan W, Arndorfer RC. Interdigestive phasic contractions of the human lower esophageal sphincter. Gastroenterology 1983; 84: 453-60.

21 Houghton LA, Read NW, Heddle R, et al. Relationship of the motor activity of the antrum, pylorus and duodenum to gastric emptying of a solid-liquid mixed meal. Gastroenterology 1988; 94: 1285-91.

22 Fisher R, Cohen S. Physiological characteristics of the human pyloric sphincter. Gastroenterology 1973; 64: 67-75.

23 Schulze-Delrieu K, Ehrlein HJ, Blum AL. Mechanics of the pylorus. In: Akkermans LMA, Johnson AG, Read NW, eds. Gastric and gastroduodenal motility. New
York: Pracger, 1984: 87-102.

24 Johansson C. Ekelund K. Relation between body weight and the gastric and intestinal handling of an oral caloric load. Gut 1976; 17: 456-62.

25 Edin $\mathrm{R}$. The vagal control of pyloric motor function. A physiological and immunohistochemical study in cat and man. Acta Physiol Scand 1980) 485 (Suppl): $1-3()$.

26 Allescher HD, Daniel EE, Dent J, Fox JET, Kostolanska F. Extrinsic and intrinsic neural control of pyloric sphincter pressure in the dog. J Physiol (Lond) 1988: 401: 17-38.

27 Allescher HD, Daniel EE, Dent J, Kostolanska F, Fox JET. Cholinergic reflex activation of canine pyloric activity from the proximal duodenum in vivo. [Abstract]. Dig Dis Sci 1987; 32: 9(0).

28 Reynolds JC, Ouyang A, Cohen S. Evidence for an opiate-mediated pyloric sphincter reflex. Am J Physiol 1984; 246 (Gastrointest Liver Physiol 9): G130-6.

29 Bovell KT. Tougas G, Dent J, Collins SM, Hunt RH. Effect of naloxone on lipid induced pyloric motor responses in humans [Abstract]. Gastroenterology 1987: 92: 1325 .

30 Fone D, Heddle R, Horowitz M, Dent J, Read N. Atropine blocks the pyloric motor response to intraduodenal dextrose in healthy volunteers [Abstract]. Gastroenterology 1988; 94: A132.

31 Liddle RA, Goldfine IR, Rosen MS, Taplitz RA. Williams JA. Cholecystokinin bioactivity in human plasma - molecular forms, responses to feeding, and relationship to gallbladder contraction. J Clin Invest 1985; 75: 1144-52.

32 McCullough AJ, Miller LJ, Service FJ, Go VLW. Effect of graded intraduodenal glucose infusions on the release and physiological action of gastric inhibitory polypeptide. J Clin Endocrinol Metab 1983; 56: 234-41.

33 MacGregor IL, Gueller R, Watts HD. Meyer JH. The effect of acute hyperglycemia on gastric emptying in man. Gastroenterology 1976; 70: 190-6.

34 Miller J, Kauffman G, Elashoff J, Ohashi H, Carter D. Meyer JH. Search for resistances controlling canine gastric emptying of liquid meals. Am J Physiol 1981; 241 (Gastrointest Liver Physiol 4): G403-15.

35 Azpiroz F. Malagelada J-R. Physiological variations in canine gastric tone measured by an electronic barostat. Am J Physiol 1985; 248 (Gastrointest Liver Physiol II): G229-37.

36 Moore JD. Dubois A. Christian PE, Elgin D, Alazraki N. Evidence for a midgastric band in humans. Gastroenterology 1986; 91: 540-5.

37 Lewis TD, Collins SM, Fox JE, Daniel EE. Initiation of duodenal acid-induced motor complexes. Gastroenterology 1979; 77: 12.17-24. 